\title{
Paisagens Integradas dos Municípios Costeiros da Foz do Rio São Francisco: Brejo Grande/SE e Piaçabuçu/AL
}

\author{
Integrated Coastal Landscapes of São Francisco Mouth River: \\ Brejo Grande/SE and Piaçabuçu/AL
}

\author{
Marco Túlio Mendonça Diniz ${ }^{1} \bowtie$ (iD), Bruna Leidiane Pereira Santana ${ }^{2} \bowtie$, Luana Pereira Lima ${ }^{3} \bowtie$ \\ Eduina Bezerra França ${ }^{4} \bowtie$, Fernanda Flores Silva dos Santos ${ }^{5} \bowtie$, Rosemeri Melo e Souza ${ }^{6} \bowtie$ \\ 1Universidade Federal do Rio Grande do Norte, tuliogeografia@gmail.com, \\ https://orcid.org/0000-0002-7676-4475 \\ 2Universidade Federal de Sergipe, bruna.leydiane@gmail.com \\ 3Universidade Federal de Sergipe, lua.luana.lima@hotmail.com \\ 4Universidade Federal de Sergipe, eduina.franca@hotmail.com \\ 5Universidade Federal de Sergipe, nandaflores-20@hotmail.com \\ 6Universidade Federal de Sergipe, rome@ufs.br
}

Recebido (Received): 20/02/2019

Aceito (Accepted): 31/05/2019

\begin{abstract}
Resumo: Os ambientes costeiros destacam-se pela complexa dinâmica condicionada pela atuação de fatores oceanográficos, hidrológicos, climáticos, geológicos e antrópicos que resulta em diferentes unidades de paisagem. Neste sentido, o trabalho objetivou classificar e analisar as unidades de paisagens considerando os geocomplexos e geofácies dos municípios de Piaçabuçu/ AL e Brejo Grande/ SE. O esboço metodológico da abordagem geossistêmica norteou a pesquisa, desenvolvida através de revisão bibliográfica, levantamento e processamento de dados cartográficos e confecção de mapas temáticos. Os processos de origem marinha, fluviomarinha e eólica, associados ao pacote sedimentar que integra as Formações Continentais Superficiais do Quaternário possibilitaram a formação de ambientes com características distintas, que integram os três (03) geocomplexos - Planície Costeira, Terraços Marinhos e Planície Fluviolagunar integrados por quatorze (14) geofácies. Nos últimos anos, a planície fluviomarinha tem apresentando algumas mudanças relacionadas ao processo de erosão marinha e atividades de carcinicultura, resultado de alterações que ocorreram na dinâmica do rio São Francisco. Quanto aos terraços marinhos, em Piaçabuçu ocorrem intercalados com depressões formadas entre os cordões litorâneos, predominando como uso o cultivo de coco-da-baía. Em Brejo Grande, os sedimentos arenosos dos terraços marinhos holocênicos têm avançado sobre a planície fluviomarinha, alterando parcialmente a vegetação do mangue. Nos ambientes que compreendem a planície fluviolagunar dos municípios verifica-se alterações nos aspectos pertinentes ao uso e ocupação do solo. Assim, a partir do mapeamento com imagens de satélites dos anos de 1984 e 2017, foi possível concluir que a atuação dos processos naturais associados à ação antrópica estão proporcionando reajustes no equilíbrio dinâmico da paisagem.
\end{abstract}

Palavras-chave: Geocomplexos; Geofáceis; Dinâmica Costeira; Uso e Ocupação do Solo. Abstract: In coastal environments, the complex dynamics are characterized by the influence of
oceanographic, hydrological, climatic, geological and anthropic factors that result in different landscape
units. In this sense, the objective of this work was to classify and analyze the landscape units considering the
geocomplexes and geofacies of the municipalities of Piaçabuç / AL and Brejo Grande / SE. The
methodological sketch of the geosystemic approach guided the research, which was developed through
bibliographical revision, survey and processing of cartographic data and creation of thematic maps. The
processes of marine, fluvial and wind origin associated to the sedimentary package that integrates the
Continental Formations of the Quaternary allowed the formation of environments with distinct
characteristics that integrate the three geocomplexes - Coastal Plains, Marine Terraces and Fluviolagunar
Plain integrated by fourteen geofacies. In recent years, the fluvial plain has presented some changes related
to the process of marine erosion and shrimp farming activities, as a result of changes that occurred in the
dynamics of the São Francisco River. As for the marine terraces, in Piaçabucu they occur interspersed with
depressions formed between the coastal cords, predominating like use the coconut-bay culture. In Brejo 
Grande, the sandy sediments of the Holocene marine terraces have advanced on the fluvial plain, partially altering the vegetation of the mangrove. In the environments that comprise the fluviolagunar plain of the municipalities, there are changes in the pertinent aspects to the use and occupation of the soil. Thus, from the mapping with satellite images from 1984 and 2017, it was possible to conclude that the natural processes associated with anthropic action are providing readjustments to the dynamic balance of the landscape.

Keywords: Geocomplexes; Geofacies; Coastal Dynamics; Use and Occupation of the Soil.

\section{Introdução}

A paisagem constitui uma categoria de análise desde o final do século XVIII e início do século XIX e tem evoluído a partir dos métodos formulados dentro do campo de conhecimento das áreas ambientais. A passagem de uma visão naturalista para um conceito mais abrangente e conjuntivo possibilitou o surgimento do conceito de Geossistema que entende a paisagem integrada a partir de uma abordagem sistêmica entre as variáveis naturais e antropogênicas.

Considerando que os diversos atributos presentes em cada sistema estão imbricados por grande complexidade, o entendimento da dinâmica nas unidades de paisagem torna-se fundamental para o estudo geossistêmico, sendo necessária a realização de classificações a fim de identificar os fatores e como estes modelam as características de determinado ambiente, bem como perceber as suas fragilidades e riscos.

A unidade de paisagem pode ser considerada uma categoria de análise geográfica (AMORIM; OLIVEIRA, 2008, p. 178), esta ideia não pode ser depreendida de estudos de autores consagrados como: Sotchava (1977), Tricart (1977), Bertrand (1972). De acordo com Bertrand (1972) a paisagem é uma determinada porção do espaço resultante da combinação dinâmica e instável de elementos físicos, biológicos e antrópicos que reagem dialeticamente uns sobre os outros, estando em perpétua evolução, nestes termos a pesquisa se utiliza do conceito geográfico de geossistema como semelhante ao de paisagem integrada estabelecido por Bolós (1981).

Diniz, Oliveira e Bernardino (2015) têm uma proposta de classificação de paisagens integradas que tenta sintetizar as ideias dos autores citados acima, esta proposta já foi aplicada com êxito no trabalho de Diniz e Oliveira (2015) com resultados semelhantes aos obtidos por Amorim e Oliveira (2008). A metodologia foi utilizada ainda em escala de 1: 250.000 no estado do Rio Grande do Norte por Diniz e Oliveira (2018).

A proposta considera a taxonomia das paisagens proposta por Bertand originalmente em 1972 e confirmada por Bertrand e Bertrand (2007). Neste trabalho diferenciamos Geossistema de Geocomplexo, sobre este termo:

Cabe destacar que contrariamente à concepção original de Bertrand, a ideia de geossistema está além de um simples nível hierárquico, fato que já havia sido mostrado por V. B. Sotchava. Bertrand (1978, apud BOLÓS, 1981), na tentativa de criar um consenso com relação ás terminologias empregadas pelos estudiosos da paisagem, admite que a definição mais lógica de geossistema é a proposta por Sotchava (1977), sendo o geossistema, da mesma maneira que o ecossitema, uma abstração e categoria de análise que não se detém à uma mera escala espacial arbitrária, de forma que o geocomplexo passou a ser uma escala de análise geográfica e o geossistema o próprio conceito base de sua teoria, ou seja, dos estudos da geografia física global. Pode-se inclusive afirmar que o geossitema está para a Geografia Física Global assim como o ecossistema está para a Ecologia. (DINIZ; OLIVEIRA; BERNARDINO, 2015, p. 54).

Os geossistemas costeiros destacam-se pela forte pressão antrópica e formas de uso e ocupação do solo. Assim o funcionamento dos sistemas ambientais está propício as transformações da paisagem, seja pela ações do homem que desenvolve distintos usos e manejos, por vezes, inapropriados que auxiliam na (des)caracterização da paisagem; ou devido as mudanças naturais ocorridas que também tendem a influenciar nas atividades desenvolvidas, uma vez que pode favorecer a expansão e inserção de uma atividade e o declínio de outra.

Assim sendo, compreender a dinâmica dos ambientes costeiros é essencial para a gestão dos territórios, isto aliado ao planejamento possibilitam mitigar ou mesmo prever a ocorrência de eventos que proporcionem impactos negativos para o meio e/ou para a sociedade. Assim, este artigo tem como objetivo mapear, classificar e analisar de forma integrada as unidades de paisagens e suas alterações entre os anos de 1984 e 
2017, considerando os geocomplexos e geofácies dos municípios de Piaçabuçu/ AL e Brejo Grande/ SE, localizados na foz do Rio São Francisco.

Os munícipios de Brejo Grande/ SE e Piaçabuçu/ AL são constituídos de diferentes paisagens, algumas definidas pela dinâmica territorial vigente em função das atividades produtivas e outras pela ação dos processos naturais.

\section{Materiais e Métodos}

A pesquisa ocorreu em diferentes etapas, primeiro realizou-se a pesquisa bibliográfica através de consultas a livros, artigos, teses, dissertações e periódicos disponíveis em meios eletrônicos e acervos públicos acerca das categorias e conceitos: paisagem, paisagem costeira, unidade da paisagem e litoral, no intuito de obter o embasamento teórico e metodológico. A metodologia se baseou, sobretudo na classificação de paisagem sistematizado por Bertrand (1972), que considera os geocomplexos e geofáceis para melhor compreensão da evolução das paisagens analisadas ao longo do tempo.

Para afinamento refinamento e resultados da pesquisa, foram realizados um levantamento de dados cartográficos, delimitados e elaborados com base na análise integrada. Fez-se necessário mapear as unidades de paisagens eminentemente imbricadas ao uso e ocupação do solo, para diferenciar as mudanças da dinâmica ambiental, sobretudo pela interferência humana.

O processamento de dados foi realizado por meio de softwares Qgis (2.16), Arcgis (10.1) e Google Earth. O Qgis (2.16) foi utilizado para elaboração do mapa de localização da área de estudo e para composição e delimitação de shapefiles dos outros mapas que foram finalizados no compositor de impressão do ArcGis (10.1). Para extração de variáveis e classificação das unidades de paisagem utilizou-se imagens do Google Earth de 1984 e 2017 que foram salvas em arquivo kml e desenvolvidas no Qgis (2.16) salvas na extensão WGV e finalizadas no compositor de impressão do ArcGis com 700 JPG.

A padronização do material geocartográfico do presente artigo, foi estabelecido em todas as bases o sistema de coordenadas Universal Transversal de Mercator (UTM), e o Datum de referência o Sistema de Referência Geocêntrico para as Américas (SIRGAS 2000). Os arquivos vetoriais (shapefiles - SHP) utilizados como base foram consultados em sites de órgãos públicos tais como: IBGE, IMA, SRH, CNES/Arbus e CPRM, assim como utilizou-se de imagens Landsat 7 e 8 Copernicus para extração de variáveis de superfície referentes a 1984 que caracterizava as unidades da paisagem e o uso e ocupação do solo, uma vez que a quantidades de nuvens impossibilitava que o mapeamento fosse delimitado apenas pelo Google Earth, como ocorreu com o mapeamento de 2017.

Para identificação dos polígonos delimitados foram determinadas duas categorizações, a primeira pelo preenchimento de cor para diferenciar as unidades de paisagem e a segunda pelas hachuras que identificam o uso e ocupação do solo sobre as unidades da paisagem.

A delimitação das unidades ocorreu a partir da interpretação integrada dos componentes da paisagem através da imagem de satélite seguida da interpretação visual diretamente na tela do computador, utilizando elementos básicos de interpretação, como cor, textura, forma, tonalidade, tamanho, sombra, padrão, adjacências e localização geográfica.

Além disso, se fez necessário a realização do trabalho de campo para fins de identificação e comprovação das unidades de paisagens e suas formas de uso e ocupação analisadas e definidas, que corrobora com os levantamentos dos referenciais teóricos, sustentando a hipótese de que as transformações nas áreas investigadas foram oriundas da ação humana, comprovadas em princípio na interpretação de fotografias aéreas e confirmadas em campo.

\subsection{Caracterização da Área}

Os estados de Alagoas e Sergipe fazem parte da composição do Baixo São Francisco. Possuem características diversificadas compondo uma gama de geossistemas associados a Planície Costeira, a Planície Fluviolagunar e aos Terraços Marinhos.

Com uma hidrografia composta, principalmente, por lagoas costeiras e canais fluviais, os municípios caracterizam-se pela grande disponibilidade de recursos hídricos, em razão da presença do rio São Francisco e seus afluentes como rio Parapuca e Paraúna. A rede de drenagem apresenta meandros e canais anastomosados, este último é característico também no rio São Francisco na altura da sede de Brejo Grande devido a existência de pequenas ilhas. 
Conforme Oliveira (2012), o município de Brejo Grande localiza-se as margens do Rio São Francisco, última cidade do estado de Sergipe, fazendo parte do rico e complexo ecossistema da Foz do São Francisco. Caracterizado também pela geração de conflitos de terra em especial pela especulação imobiliária. Sua fisiografia apresenta uma forma de "relevo de superfície pediplanada e dissecada, com colinas e aprofundamento de drenagem muito fraco" (SEMARH, 2011).

Piaçabuçu, por sua vez, situa-se a $10^{\circ} 40^{\prime} 55^{\prime \prime}$ S e $36^{\circ} 43^{\prime} 44^{\prime}$ ' SW, fazendo limite com Feliz Deserto, Rio São Francisco e o Oceano Atlântico. O clima predominante é o tropical quente e seco, com ocorrência de topoclima úmido (MELO e SOUZA, 2007). Os municípios de Brejo Grande/SE e Piaçabuçu/AL, apesar de próximos, separados apenas pelo Rio São Francisco, possuem singularidades e particularidades que incluem características fisiográficas e socioculturais que os definem e os distinguem (Figura 1).

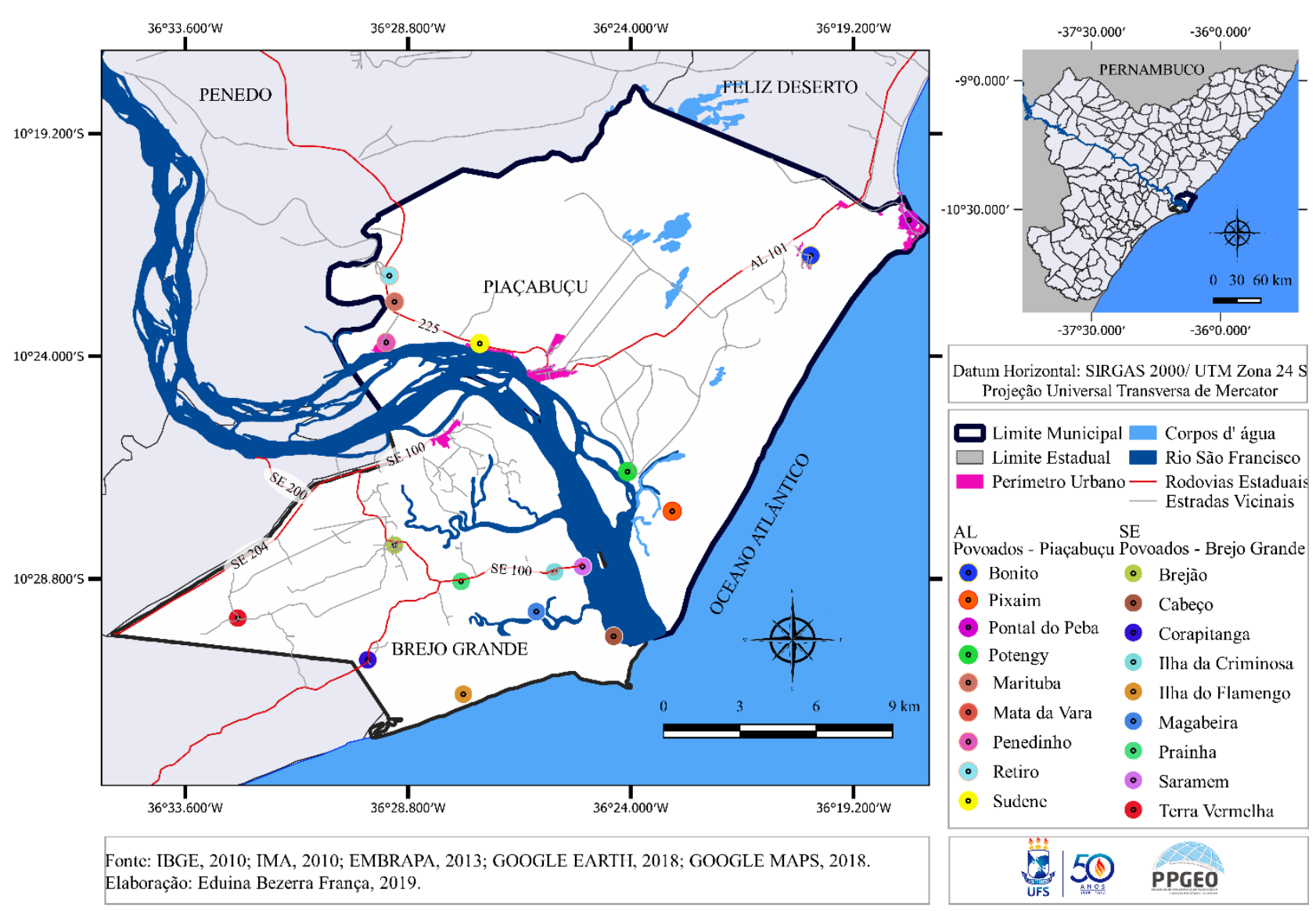

Figura 1: Localização da Área de Estudo

$\mathrm{Na}$ área de estudo, que compreende os municípios da foz do São Francisco, foram identificados três geocomplexos: Planície Costeira, Terraços Marinhos e Planície Fluviolagunar. A organização atual da paisagem que compreende esses geocomplexos nos municípios de Brejo Grande e Piaçabuçu é resultado de uma sucessão de eventos paleoclimáticos ocorridos durante o Quaternário, como as oscilações no nível dos oceanos.

Bittencourt et al (1983) descreve a evolução paleogeográfica quaternária da costa de Sergipe e sul de Alagoas em seis eventos que explicam o mecanismo de sedimentação das coberturas superficiais pliopleistocênicas. Ocorreram três grandes episódios transgressivos (Transgressão mais Antiga, Penúltima Transgressão e Última Transgressão) com predomínio de processos erosivos, trabalhando e retrabalhando feições formadas em períodos anteriores. E três eventos regressivos subsequentes a cada um desses episódios onde predominaram os processos de agradação.

Os principais estágios evolutivos que atuaram na zona costeira estão descritos nos três últimos eventos (Figura 2). No quarto estágio - Regressão subsequente à Penúltima Transgressão - foram construídos os terraços marinhos pleistocênicos, cobertos por cristas praiais, a partir das falésias da Formação Barreiras e dos remanescentes dos depósitos de leques aluviais coalescentes. 


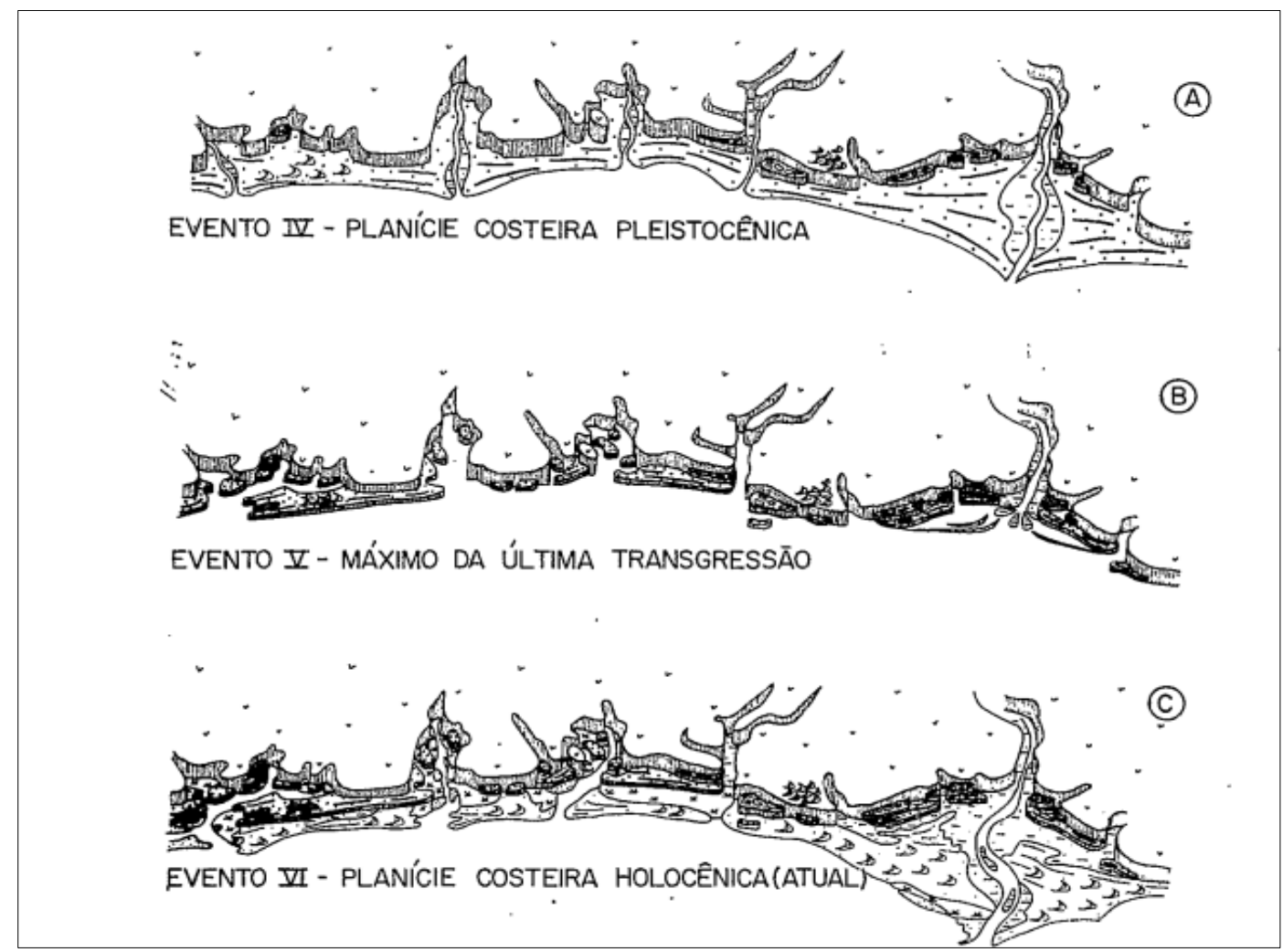

Figura 2: Esquema da evolução paleogeográfica do Quaternário da costa do Estado de Sergipe e da Costa Sul do Estado de Alagoas. Fonte: BITTENCOURT et al. (1983).

No quinto estágio - máximo da Última Transgressão - o nível relativo do mar atingiu um máximo de 4 a $5 \mathrm{~m}$ acima do nível médio atual. Os terraços marinhos pleistocênicos foram parcialmente erodidos. Os rios foram pela última vez afogados formando uma série de corpos lagunares. O estágio posterior - Última Regressão - deu ao modelado da costa do estado de Sergipe e sul de Alagoas as formas finais.

\section{Resultados}

Cada um dos geofácies foi mapeado como unidades de paisagem em dois períodos, 1984 e 2017. No mapeamento de 1984 estão identificadas as unidades de paisagem sem a atribuição do uso e ocupação do solo (com exceção das áreas urbanas), pois eram pouco expressivos na paisagem (Figura 3), por isso só identificou-se 09 (nove) geofácies. Constatou-se que as alterações na paisagem ocorreram de forma mais intensa no município de Piaçabuçu (Figura 4), devido a facilidade de acesso pela Rodovia AL-101, o município de Brejo Grande tem paisagens mais conservadas, devido especialmente á dificuldade de acesso à essas paisagens.

Já no ano de 2017 os processos de origem marinha, fluviomarinha e eólica; o pacote sedimentar que integra as Formações Continentais Superficiais do Quaternário e a ocupação humana possibilitaram a formação de ambientes com características distintas, que integram os três (03) geocomplexos onde foram identificados quinze (15) geofácies em 2017, incluindo as áreas urbanas (Tabela 1; Figura 4). 


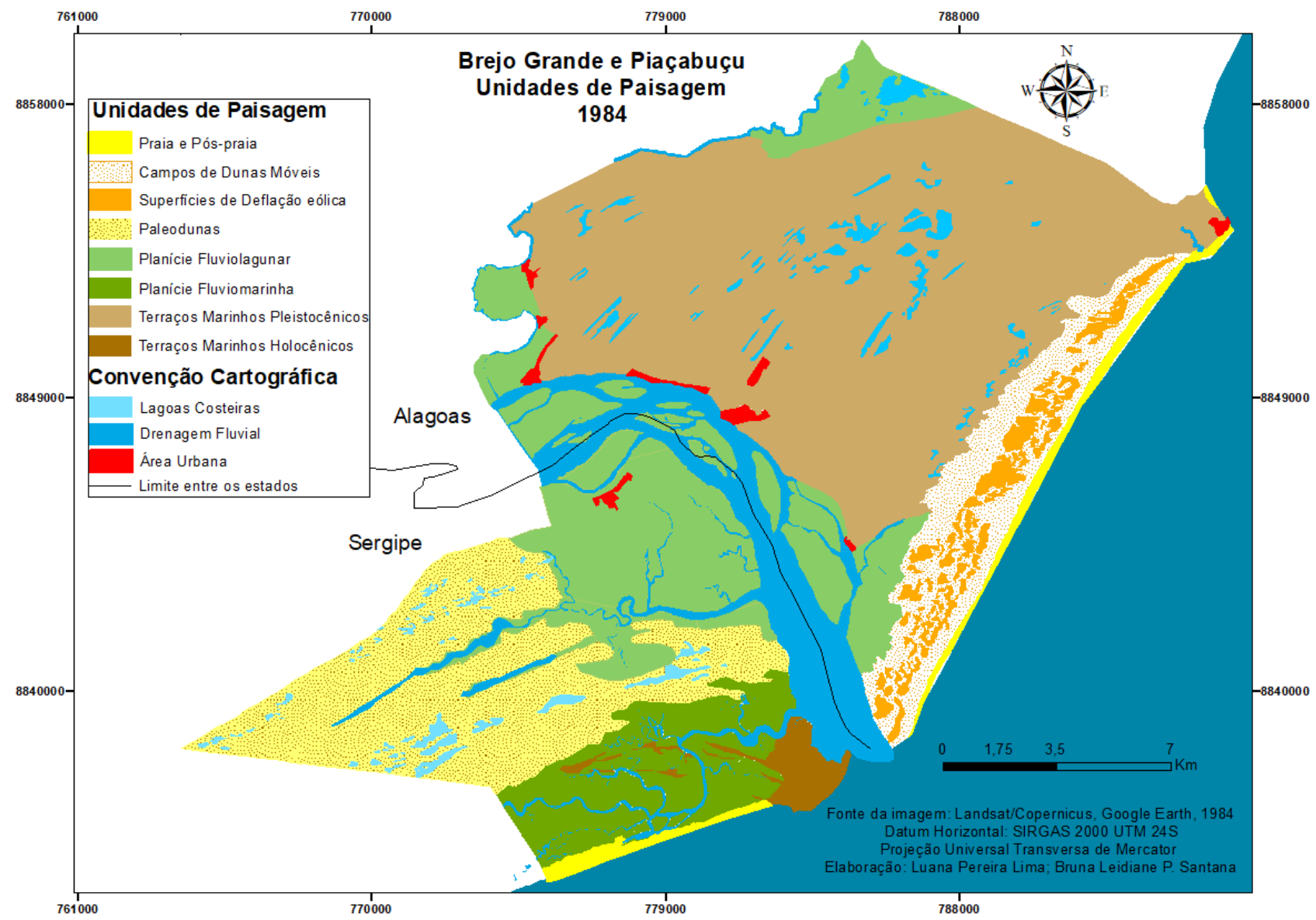

Figura 3: Unidades de paisagem identificadas nos municípios de Piaçabuçu e Brejo Grande em 1984.

Tabela 1: Geocomplexos e geofáceis identificados nos municípios de Piaçabuçu e Brejo Grande em 2017. GEOCOMPLEXO GEOFÁCIES - UNIDADES DE PAISAGEM

Praia e Pós-praia

Superfície de Deflação Eólica

Planície Costeira

Campos de Dunas Móveis

Vegetação de Restinga sobre Paleodunas

Manguezal

Carcinicultura sobre Planície Fluviomarinha

Terraço Marinho Holocênico

Terraços Marinhos

Terraço Marinho Pleistocênico com gramíneas e solo exposto

Terraço Marinho Pleistocênico com vegetação de restinga

Terraço Marinho Pleistocênico com cocoicultura.

Planície Fluviolagunar

Planície Fluviolagunar

Rizicultura sobre Planície Fluviolagunar

Fruticultura e Pastagem sobre Planície Fluviolagunar

Policultura sobre Planície Fluviolagunar 


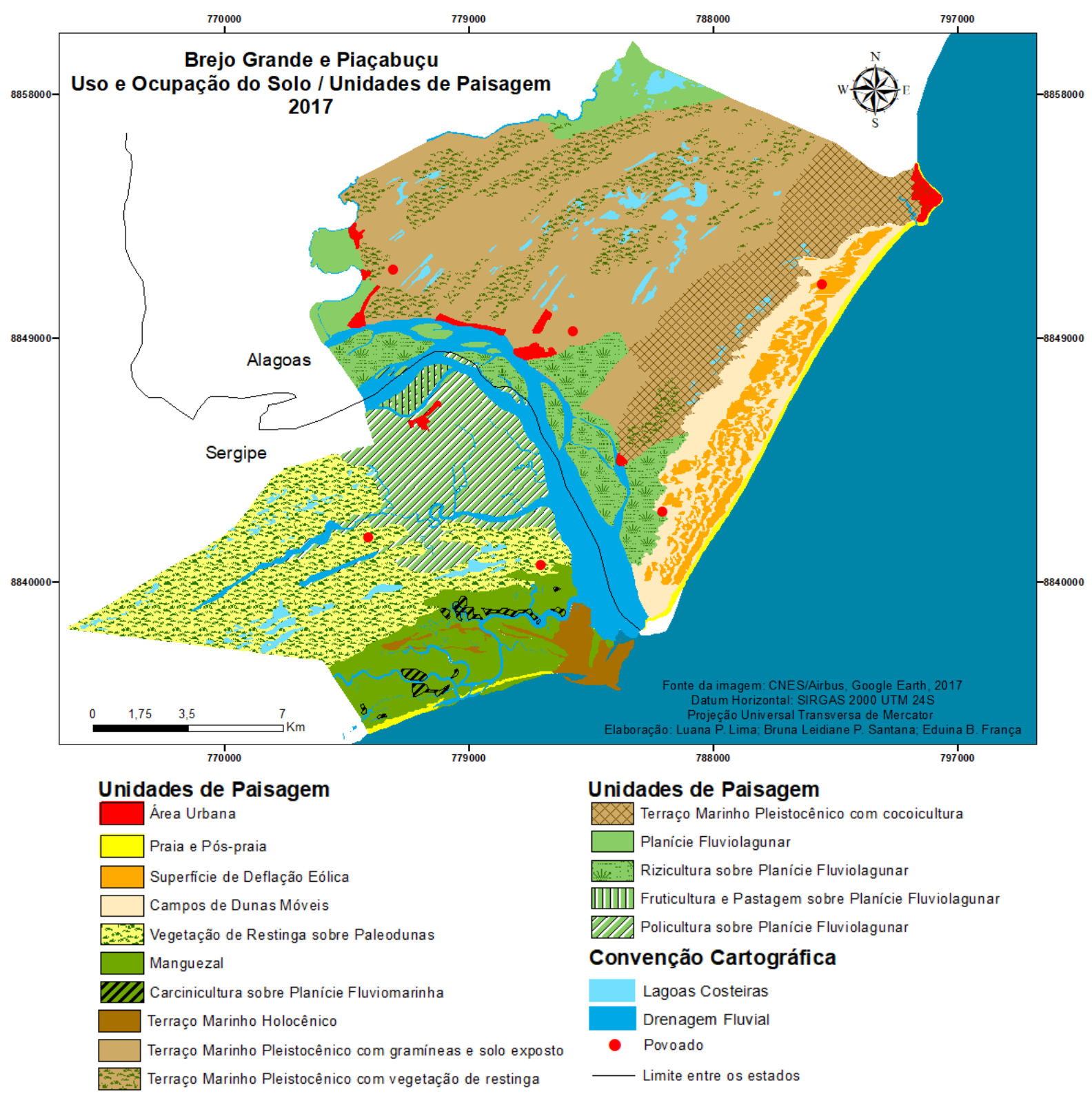

Figura 4. Unidades de paisagem identificadas nos municípios de Piaçabuçu e Brejo Grande em 2017

Na Tabela 2 é possível identificar a variação da dimensão das unidades de paisagem entre os anos de 1984 e 2017 nos municípios estudados.

Tabela 2. Área em $\mathrm{Km}^{2}$ dos Geocomplexos e das geofácies elaborados pela dinâmica natural em Piaçabuçu e Brejo Grande.

\begin{tabular}{|c|c|c|c|c|c|c|}
\hline GEOCOMPLEXO & $\begin{array}{l}\text { UNIDADE DE } \\
\text { PAISAGEM } \\
\text { PIAÇABUÇU }\end{array}$ & 1984 & 2017 & $\begin{array}{c}\text { UNIDADE DE } \\
\text { PAISAGEM BREJO } \\
\text { GRANDE }\end{array}$ & 1984 & 2017 \\
\hline $\begin{array}{c}\text { Planície } \\
\text { Fluviolagunar }\end{array}$ & 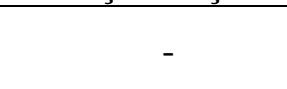 & 30,5 & 30,7 & 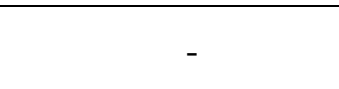 & 70,5 & 70,5 \\
\hline \multirow{4}{*}{ Planície Costeira } & $\begin{array}{l}\text { Superfícies de } \\
\text { deflação eólica }\end{array}$ & 9,8 & 13,7 & $\begin{array}{c}\text { Planície } \\
\text { fluviomarinha }\end{array}$ & 29,8 & 26,8 \\
\hline & $\begin{array}{c}\text { Campos de dunas } \\
\text { móveis }\end{array}$ & 32,8 & 34,9 & Paleodunas & 60,0 & 60,0 \\
\hline & Praia e pós-praia & 4,5 & 2,5 & \multirow{2}{*}{$\begin{array}{c}\text { Praia e pós-praia } \\
\text { Terraços Marinhos } \\
\text { Holocênicos }\end{array}$} & 1,8 & 0,81 \\
\hline & $\begin{array}{c}\text { Terraços } \\
\text { Marinhos } \\
\text { Pleistocênicos }\end{array}$ & 156,1 & 155,9 & & 6,69 & 4,3 \\
\hline
\end{tabular}




\section{Discussões}

Segundo Bertrand e Bertrand (2007) o geocomplexo situa-se entre $4^{\mathrm{a}}$ e $5^{\mathrm{a}}$ grandeza têmporo-espacial de Cailleux e Tricart (1956), compreendida entre alguns quilômetros quadrados até centenas de quilômetros quadrados, é nesta escala que se situa a maior parte fenômenos de interferência entre os elementos sociais e naturais das paisagens integradas. Diniz, Oliveira e Bernardino (2015) propõem que sejam mapeados em escala de $1 / 250.000$ a $1 / 50.000$.

Ainda segundo Bertrand e Bertrand (2007) os geocomplexos não apresentam necessariamente uma grande unidade fisionômica, daí a importância em mapear geofácies, o sufixo fácies aqui refere-se exatamente à fisionomia, assim os geofácies são unidades de paisagem que têm identidade fisionômica, por isso são consideradas as formas de uso do homem, dado que a ocupação altera a fisionomia das paisagens. Diniz, Oliveira e Bernardino (2015) propõem que sejam mapeados em escala de 1/50.000 a 1/10.000, nesta pesquisa as unidades foram mapeadas em 1/25.000.

Os três geocomplexos e seus geofácies são discutidos a seguir.

\subsection{Planície Costeira}

Tem suas paisagens mais recentes no tempo geológico, foram elaboradas durante o quinto e o sexto eventos descrito por Bittencourt et al. (1983) e citados anteriormente, se tratam de paisagens formuladas entre a transgressão e posterior regressão holocênicas, a planície resulta da sobreposição de depósitos eólicos litorâneos e marinhos atuais nos terraços marinhos, constituídos de sedimentos arenosos, bem selecionados, com grãos arredondados de areia, modelados pela ação eólica no caso das dunas. Na área de estudo têm-se a presença de campos de dunas móveis e paleodunas.

Os campos de paleodunas de feição parabólica ocupam a maior parte do município de Brejo Grande, estas dunas se formaram quando da transgressão holocênica, nesta época seu máximo se deu há 5.100 A.P. (BITTENCOURT et al., 1983) A estabilidade inerente a essas feições deve-se a vegetação de restinga ( sobre Neossolos Quartzarênicos Hidromóficos caracterizados pela baixa fertilidade e suscetibilidade aos processos eólicos, além disso, são solos de textura arenosa que permitem rápida infiltração da água dificultando a ação do escoamento superficial e a retenção hídrica.

No município de Piaçabuçu, os campos de dunas móveis tiveram pequeno crescimento espacial, passando de 32,8 para 34,9 km² (Tabela 2), o que se deveu à dinâmica natural, estas dunas encontram-se distribuídas em uma ampla área intercalada por superfícies de deflação, ambos formados durante a regressão holocênica. Nestes ambientes, sujeitos a intensa atividade morfodinâmica, atuam os processos naturais hidrodinâmicos marinhos e eólicos.

As superfícies de deflação eólica tiveram acréscimo ainda maior em sua área, passando de 9,8 para 13,7 $\mathrm{km}^{2}$, o que evidencia que houve disponibilidade de sedimentos das praias mobilizados paras as dunas móveis e superfícies de deflação, umas que estas evidenciam a migração dos campos de dunas móveis. Nestas áreas de deflação eólica ocorre a retirada de material da superfície pela ação eólica. Em Piaçabuçu há locais de forte e constante deflação, tanto que permitiram a formação de zonas rebaixadas que atingem o lençol freático, conformando uma paisagem úmida sazonal, com vegetação do tipo rasteira. Estas unidades de paisagem, em Piaçabuçu, são protegidas por uma Unidade de Conservação: APA de Piaçabuçu.

Encontram-se também em Piaçabuçu e Brejo Grande, praias arenosas. Segundo Diniz (2008), a praia e pós-praia fazem parte de uma unidade de paisagem situada a partir da interface entre o oceano e continente adentro até onde houver ausência de solos e consequentemente de vegetação, ou até encontrar os campos de dunas. Trata-se de um ambiente costeiro, sedimentar e exposto a ação das ondas. No caso das praias e póspraias arenosas, esses sedimentos são inconsolidados.

Além disso, constituem ambientes de grande dinamicidade, no qual os sedimentos são trabalhados e retrabalhados por ondas, correntes, marés, constantemente alterados pela ação marinha e antrópica. Esse balanço sedimentar ao longo dos anos pode apresentar-se negativo ou positivo, ou seja, podem apresentar erosão ou acúmulo.

Em ambos os municípios houve diminuição da unidade correspondente a praia e pós-praia. Passou-se de 4,5 $\mathrm{km}^{2}$ para 2,5 $\mathrm{km}^{2}$ no município alagoano e de $1,8 \mathrm{~km}^{2}$ para $0,8 \mathrm{~km}^{2}$ no município sergipano. No município sergipano a erosão costeira tem sido atribuída à barragem do Rio São Francisco (BITTENCOURT; OLIVEIRA, DOMINGUEZ, 2006), que acarretou a diminuição da descarga sólida do São Francisco, o que foi confirmado por Dominguez et. al., (2016). No município alagoano parte do póspraia foi convertido em superfície de deflação ou em dunas móveis, a erosão não é problema reconhecido ao 
norte da Foz do São Francisco, mais sim ao sul desta, dado que a dinâmica de corrente longitudinal da área é predominante para sul (DINIZ, et. al., 2016). Outra parte das praias de Piaçabuçu foi ocupada pela expansão urbana no Pontal do Peba.

Mesmo sem a forte pressão antrópica direta nesta unidade, faz-se necessária a preocupação com o uso e ocupação do solo no futuro, visto que são meios instáveis e de fragilidade acentuada.

Quanto à planície fluviomarinha, na área de estudo ocorre somente no município de Brejo Grande entre os terraços marinhos e as paleodunas, esta unidade teve sua área diminuída de 29,8 para $26,8 \mathrm{~km}^{2}$. São ambientes atuais, assim como as praias.

É uma unidade com uma a dinâmica condicionada por processos marinhos e constituída por sedimentos argilo-siltosos, ricos em matéria orgânica, denominados depósitos de pântanos e mangues, que possibilitaram a evolução dos gleissolos sálicos, solos halomórficos pouco desenvolvidos, lamacentos, escuros e com alto teor de sais provenientes da água do mar. O que é indicativo de discordância deposicional entre as duas áreas da foz do São Francisco, a área de Brejo Grande mais próxima ao oceano teve sua deposição em ambiente flúvio-marinho, já a área mais frontal ao atlântico de Piaçabuçu teve deposição em ambiente emerso (deposição eólica) durante o holoceno.

A combinação singular entre as águas fluviais e marinhas favoreceu o desenvolvimento do ecossistema manguezal, de elevada produtividade biológica, de grande importância para a reprodução de inúmeras espécies de peixes e crustáceos, bem como das espécies da flora, localmente representada pelos Mangues Bravo ou Vermelho (Rhizophora mangle) e Manso ou Branco (Laguncularia racemosa).

Nos últimos anos, a planície fluviomarinha tem apresentando algumas mudanças relacionadas ao processo de erosão marinha e atividades de carcinicultura, resultado de alterações que ocorreram na dinâmica do rio São Francisco o que foi responsável pela diminuição da área desta unidade, conforme exposto. A diminuição da vazão e do aporte sedimentar no curso do rio, atribuído a construção de barragens como a de Xingó, tem intensificado o processo de erosão na margem direita da sua foz. Como resultado observa-se a erosão das praias, recuo da linha de costa e a deposição de grande volume de sedimentos praiais arenosos na Planície fluviomarinha provocando o soterramento e morte do mangue (Figura 5(A) e $(\boldsymbol{B}))$.

Conforme Santana et. al. (2016), devido ao avanço da cunha salina no canal fluvial, que também alcança os tributários do rio São Francisco e lagoas onde se pratica a rizicultura, os rizicultores estão optando por novas atividades produtivas, a exemplo da carcinicultura, em razão do prejuízo.
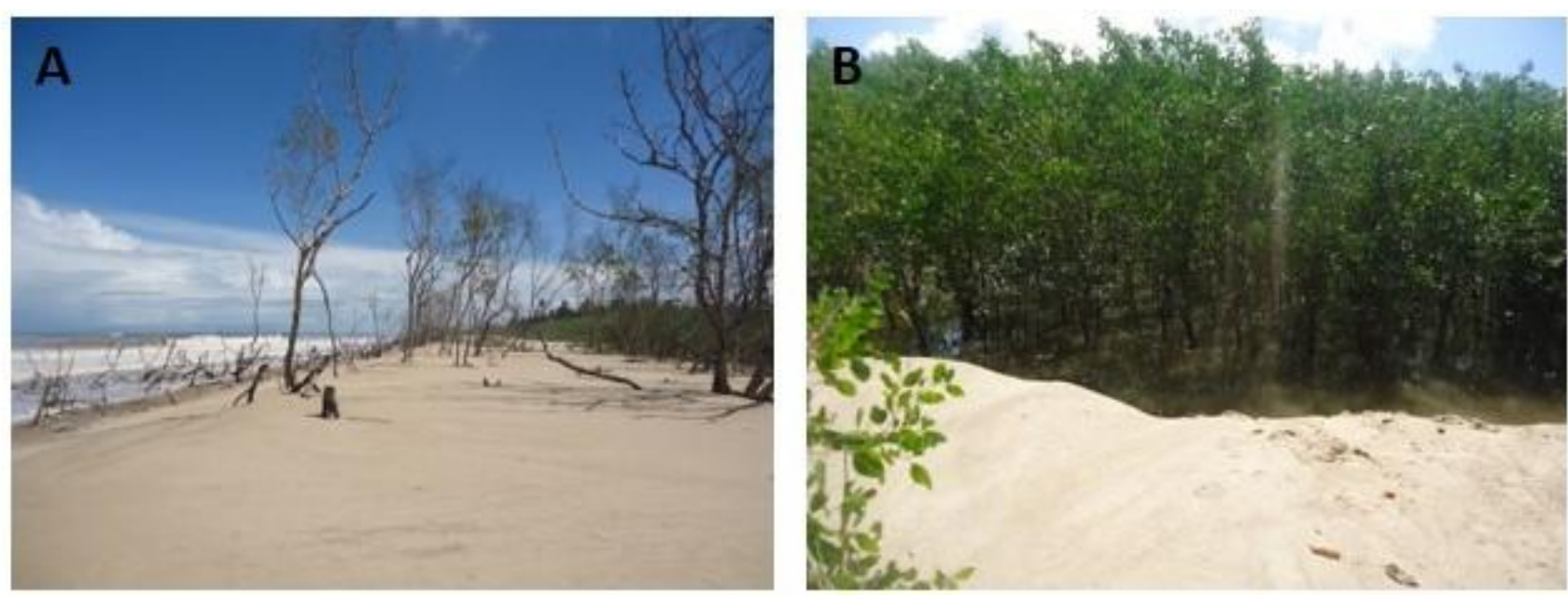

Figuras 5: $(\boldsymbol{A})$ e (B). Soterramento do mangue em Brejo Grande/SE por areais praiais. Fonte: Atividade de campo em maio de 2018.

A carcinicultura por sua vez, se apresenta com forte interesse socio-econômico e se insere como elemento fundamental no processo de transformação da paisagem. Rodrigues e Kelting (2010) compreendem como recurso natural presente nas planícies fluviomarinhas, o ambiente estuarino passou a ser explorado economicamente por carcinicultores, uma vez que, o estuário apresenta uma área própria para efetivar essa prática, sendo necessário a fixação de equipamentos específicos para implantação que provocam modificações na paisagem local.

A carcinicultura diz respeito ao cultivo e produção comercial de camarão marinho que nas últimas décadas se tornou alternativa para produtores rurais no Estado de Sergipe, com abrangência no munícipio de 
Brejo Grande, extremo norte do litoral sergipano. A carcinicultura no município, foi implantada de forma desordenada, ocupando áreas anteriormente destinadas a atividades (rizicultura, cocoicultura, piscicultura e sal marinho) de comunidades tradicionais, sendo também implantadas em áreas de manguezal, que ocasionou a perda da vegetação pioneira (ILHA, 2017). Ainda de acordo com o referido autor, o adensamento da carcinicultura em Brejo Grande, se concentra em aproximadamente 100 hectares distribuídos nas ilhas do Capim, Sal e Flamengo e no Porto Pau da Gamela.

Em suma, a carcinicultura é um atividade que provoca o desequilíbrio ecológico do ecossistema manguezal naturalmente sensível à alteração. A instalação das piscinas artificiais resulta na supressão da vegetação de restinga. $\mathrm{O}$ constante uso de fertilizantes inorgânicos em associação com as sobras da ração provocam o acúmulo de sais no fundo dos viveiros que são liberados nos cursos de água sem tratamento prévio, contribuindo para processo de eutrofização das águas.

Outro fator negativo, desencadeado pela carcinicultura no sistema ambiental, é a introdução da espécie exótica Litopenaeus vannamei, conhecido como camarão-de-patas-brancas ou camarão-branco-do-pacífico. Sua inserção nos corpos d'água por despesca ou desmoronamento do talude de viveiros, acarreta alterações nos ecossistemas aquáticos, modificando a cadeia trófica.

\subsection{Terraços Marinhos}

Os terraços marinhos são acumulações arenosas em área plana, levemente inclinada para o mar, apresenta ruptura de declive em relação a planície marinha recente e variação de nível marinho e/ou por movimentação tectônica (FORMOSO, 2008). Os terraços marinhos ao longo da costa do estado de Sergipe e da costa Sul de Alagoas correspondem a penúltima e a última transgressão marinha.

Os terraços marinhos pleistocênicos foram formados ao longo da regressão que se sucedeu após a transgressão pleistocênica que teve máximo em 120.000 A.P. (BITTENCOURT et al., 1983), "apresentam na superfície uma camada clara seguida de outra de coloração mais escura que aumenta de intensidade de cima para baixo, resultante da impregnação por ácidos húmicos e, ou, óxido de ferro" (ARAÚJO, 2015, p. 2). Já os terraços marinhos holocênicos "apresentam na superfície contínuas e bem marcadas cristais de cordões litorâneos, estreitamente próximos e paralelos entre si” (BITTENCOURT, et al, 1983, p. 94).

Em Piaçabuçu o terraço marinho pleistocênico é a unidade mais significativa em termo de extensão territorial e teve suas dimensões espaciais praticamente inalteradas entre 1984 e 2017, passando de 156,1 para $155,9 \mathrm{~km}^{2}$, a alteração se deu devido à pequena expansão da área urbana sobre esta unidade sendo um dos geofácies naturais mais estáveis da área. Esta morfologia apresenta altitude que varia entre 6 e 8 metros, intercaladas com depressões formadas entre os cordões litorâneos, conferindo à superfície um aspecto ondulado. Nas áreas deprimidas entre os cordões se instalaram lagoas freáticas de caráter temporário ou permanente.

Quanto a evolução pedogenética, o material de origem associada às condições climáticas propicia o desenvolvimento dos Neossolos Quartzarênicos que ocorrem nas áreas mais elevadas e Espodossolos Humilúvicos presentes nas áreas deprimidas com elevada umidade. Os Neossolos Quartzarênicos caracterizam-se pelo excessivo potencial de drenagem e pela resistência do material de origem ao intemperismo, que dificulta a atuação dos processos pedogenéticos. Estes solos arenoquartzosos são ocupados pela vegetação de restinga herbácea e arbustiva que fixam os sedimentos, dificultando a ação morfodinâmica.

Os terraços marinhos holocênicos por sua vez, são depósitos arenosos, associados a cordões litorâneos, se caracterizam pela variação de altitude entre 2 e 4 metros e estão "posicionados sobre as plataformas de abrasão em rochas sedimentares tipicamente continentais (Formação Barreiras)" (MEIRELES; RAVENTOS, 2002 , p. 89). Esse tipo de terraço se constituí de sedimentos praiais, ricos em restos de conchas e minerais pesados e em sua maioria se encontram cobertos por sedimentos eólicos, foram formados durante a regressão que se sucedeu à transgressão holocênica já descrita. Esta unidade está presente apenas em Brejo Grande e teve sua área diminuída de 6,7 para $4,3 \mathrm{~km}^{2}$.

Em Brejo Grande os terraços marinhos holocênicos, configuram uma feição com suave mergulho em direção ao oceano e conta com uma praia originada pela deposição de sedimentos arenosos, resistentes a atuação dos processos pedogenéticos.

Em razão dos eventos que têm ocasionado a intensa erosão na margem direita na foz do rio São Francisco, onde se concentram os terraços marinhos de Brejo Grande, cabe salientar que devido às transformações da paisagem os sedimentos arenosos dos terraços marinhos holocênico tem avançado sobre a 
planície fluviomarinha, sendo esta a principal razão da diminuição da área desta unidade, alterando parcialmente a vegetação do mangue, sobretudo no povoado Barra das Costinhas.

Em relação ao uso do solo mapeável na escala deste trabalho ele se restringe aos terraços pleistocênicos, destaca-se o cultivo de coco-da-baía principalmente em Piaçabuçu, um dos grandes produtores de coco do Nordeste. Neste município o cultivo ocorre nos terraços marinhos pleistocênicos que apresenta condições de solos e disponibilidade hídrica favorável. Na paisagem de Brejo Grande a cocoicultura está integrada em áreas de vegetação de restinga, em diferentes estágios de preservação.

\subsection{Planície Fluviolagunar}

A Planície Fluviolagunar é um dos geocomplexos que integra a paisagem da área de estudo. As características morfológicas dessa unidade apresentam uma associação com os aspectos geológicos e paleoclimáticos que atuaram na configuração geomorfológica durante o quaternário e como resultado têm-se uma paisagem com formas pretéritas e atuais sobrepostas, subordinadas aos processos morfodinâmicos do presente (ALVES, 2010).

Este geocomplexo resulta de processos de sedimentação de ambientes lagunares e fluviais, sendo constituídos litologicamente por sedimentos do quaternário (siltes, argilas e areias) ricos em matéria orgânica que "foram depositados em antigas lagunas formadas durante a parte terminal da última transgressão que, tendo cortadas suas comunicações com o mar na regressão subsequente, foram colmatadas e evoluíram para pântanos" (CPRM, 2007, p.52).

Nos municípios de Piaçabuçu e Brejo Grande os depósitos fluviolagunares formam uma planície com altitude por volta de $4 \mathrm{~m}$ e ocupam, principalmente, as proximidades do rio São Francisco. No município alagoano, está presente em sua porção noroeste, banhada pelo rio Marituba e superfícies alagadiças, e em toda a extensão de terra banhada pelo rio São Francisco. No município sergipano, está presente na porção noroeste banhada pelo Rio São Francisco e alguns dos seus afluentes.

Em grande parte da planície fluviolagunar estão presentes os Vertissolos Hidromórficos. São compostos por material mineral argiloso a muito argiloso, com alto teor de argila expansivas. Apresentam horizonte vértico que referem-se a um horizonte mineral subsuperficial que, devido à expansão e contração das argilas, apresenta feições pedológicas típicas, que são as superfícies de fricção (slickensides) em quantidade no mínimo comum. O horizonte vértico pode coincidir com horizontes $\mathrm{AC}, \mathrm{B}$ (Bi ou Bt) ou $\mathrm{C}$ e apresentar cores escuras, acinzentadas, amareladas ou avermelhadas (SANTOS et al., 2018).

A pequena variação textural ao longo do perfil deste solo resulta em pronunciadas mudanças de volume conforme o teor de água no solo. São pouco desenvolvidos, variam de pouco profundos a profundos. Possuem consistência muito plástica e pegajosa, quando molhados, devido à presença de argilas expansíveis ou mistura destas com argilominerais, e muito dura a extremamente dura, quando secos. Quanto à drenagem, variam de imperfeitamente a mal drenados, e quando úmidos têm permeabilidade à água muito lenta. Em termos de cor, podem ser escuros, acinzentados, amarelados ou avermelhados (SANTOS et. al. 2018).

Nos ambientes que compreendem as planícies fluviolagunares sua área se manteve estável, sem variação em Brejo Grande com 70,5 km², e com pequena variação em Piaçabuçu passando de 30,5 para 30,7 km² entre os anos de 1984 e 2017. Não houveram mudanças significativas em termos de área nos dois municípios, mas sim em termos de uso, a área deste geocomplexo é a mais usada pelo homem nos dois municípios.

Neste contexto do uso e ocupação das terras, o geocomplexo Planície Fluviolagunar subdivide-se em Rizicultura sobre Planície Fluviolagunar, Fruticultura e Pastagem sobre Planície Fluviolagunar e Policultura sobre Planície Fluviolagunar.

A dinâmica nas planícies fluviolagunares caracterizada pelas periódicas inundações propiciou um ambiente favorável ao cultivo de arroz (Figura 6), que foi por algumas décadas a principal atividade produtiva da área de estudo gerando postos de trabalho e contribuindo no desenvolvimento econômico do município. Contudo, diferentes fatores naturais e antrópicos têm contribuído para seu declínio.

Atualmente, o problema que expressa maiores prejuízos a rizicultura é a salinização das águas fluviais. Este processo ocorre pelo avanço da cuia salina sobre o rio São Francisco e seus afluentes, resultando na elevação do teor de sal das águas que chegam as lagoas de arroz interferindo no crescimento do grau e consequente na redução da produtividade. 


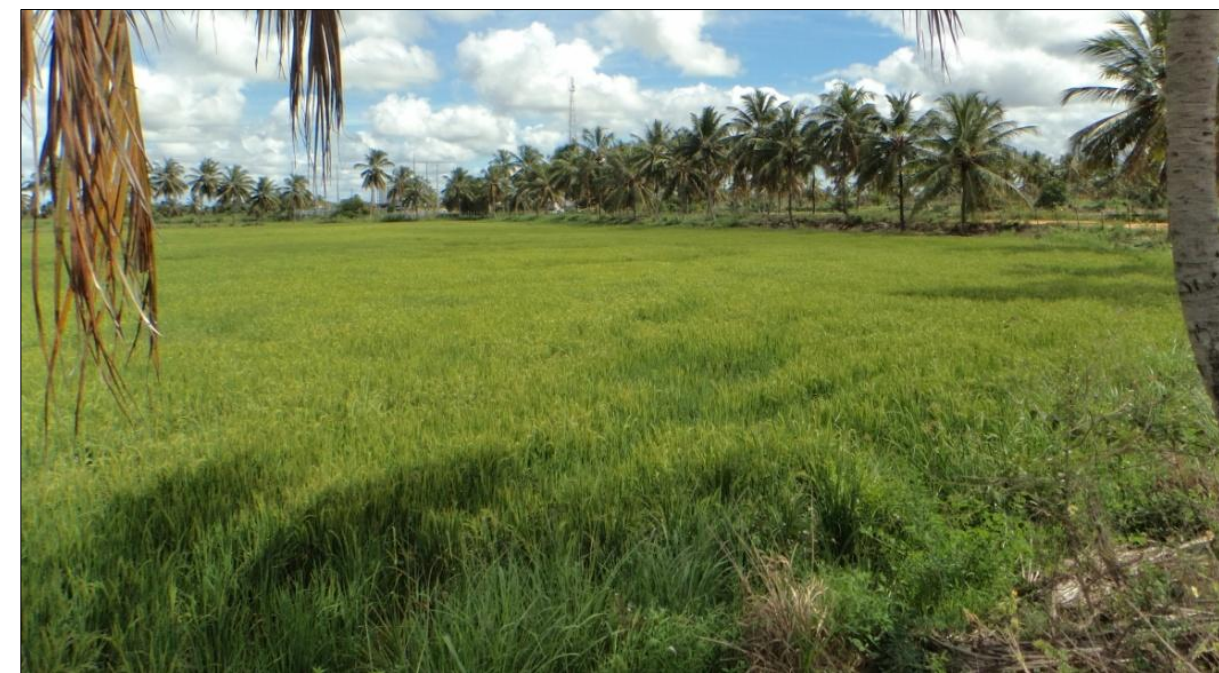

Figura 6: Plantio de arroz sobre a Planície Fluviolagunar em Brejo Grande/SE. Fonte: Atividade de campo em maio de 2018

As áreas mais próximas a foz do rio São Francisco como o povoado Resina, em Brejo Grande, a atividade tem diminuído significativamente e está sendo substituída pela carcinicultura que se tornou a atividade em expansão (ALVES et al., 2017). No povoado Poxim em Piaçabuçu, a salinização impossibilitou a produção de arroz, acarretando na perda de identidade, uma vez que a comunidade está se desconstituindo pela necessidade de buscar novas oportunidades.

As mudanças ocorridas na rizicultura atingem diretamente as pessoas que têm sua renda familiar dependente da atividade econômica. Deve-se ressaltar ainda que as técnicas empregadas no processo produtivo como maquinário utilizado na colheita e processamento do arroz são responsáveis também pela redução dos postos de trabalho.

Além da rizicultura uma pequena parcela da Planície Fluviolagunar, no município de Brejo Grande, caracteriza-se pela ocorrência de frutíferas nativas, como mangabeiras e cajueiros intercalados com pastagem natural. No município este geocomplexo é ocupado também por policultura de frutíferas associadas à culturas temporárias.

\subsection{Povoados e Área Urbana}

São geofácies espalhadas por pelos 3 geocomplexos. O município de Brejo Grande se constitui de uma sede municipal e um pouco mais de quarenta (40) localidades que se dividem em sítios, ilhas e povoados. Se destacam quatro povoados: Saramém conhecido pelas atividades de pesca e turismo; antigo Farol do Cabeço, hoje totalmente submersa; Brejão, considerado o distrito e o maior povoado do munícipio com uma economia baseada no turismo, arroz, coco e pecuária; e Terra Vermelha, rico em belezas naturais e culturalmente conservado por manter a característica da etnia de seus colonizadores holandeses. Brejo Grande/ SE, concentra uma economia em agricultura (arroz, coco, manga e mandioca), pecuária (ovinos, bovinos, suínos e equinos), avicultura pouco desenvolvida e a pesca artesanal.

O munícipio de Piaçabuçu tem como áreas de abrangências a sede municipal e oito povoados sendo: Sudene, Penedinho, Marituba, Retiro, Pontal do Peba, Bonito, Pixaim, Pontegy, (esses quatro últimos compreende a APA de Piaçabuçu). Segundo o ICMBio (2010) a atividade que ocupa a maior área de Piaçabuçu é a cocoicultura, assim como, o arroz já foi destaque nos cultivos do município, mas atualmente é quase inexistente a sua produção, sendo assim, as principais lavouras temporárias encontradas são: mandioca, feijão e milho e em relação a pecuária a atividade desenvolvida é o gado de leite. Cabe salientar que a atividade em que ocupa maior número de trabalhadores é a pesca que se executa no mar, rios, principalmente no São Francisco e nas lagoas naturais. Além desses, uma prática muito comum na área é o turismo, sobretudo em Pontal do Peba, no povoado Pixaim, onde se encontram as dunas móveis e na foz do São Francisco. 


\section{Conclusões}

Neste estudo foi realizada uma análise integrada da paisagem, que possibilitou identificar quais componentes naturais interferiram nos processos morfodinâmicos ao longo do tempo e de que modo a ação antrópica influencia a dinâmica ambiental a partir do uso e ocupação do solo.

Dessa forma, através da classificação das unidades de paisagens nos municípios de Brejo Grande/SE e Piaçabuçu/AL identificou-se que os processos de origem marinha, fluviomarinha e eólica associados ao pacote sedimentar possibilitaram a formação de ambientes com características distintas. A partir do mapeamento através do uso de imagens de satélites dos anos de 1984 e 2017, foi possível concluir que a atuação dos processos naturais em conjunto com os fatores antrópicos, intensificados pelo modo de uso e ocupação do solo, estão proporcionando uma alteração no equilíbrio dinâmico da zona costeira analisada.

A metodologia utilizada considerou a fisionomia como principal critério para a delimitação dos geofácies, essa técnica foi importante para cartografar as paisagens em recortes temporais distintos e se apresentou eficiente para compartimentar os geocomplexos, foi possível associar assim as atividades humanas, especialmente as rurais, aos componentes do potencial ecológico e exploração biológica. A limitação dessa técnica reside no fato de que ela representa um momento, pois alteradas as atividades de uso e ocupação do solo, são alteradas junto as geofácies, como pode ser percebido ao comparar o mapa de 1984 com o de 2017.

Considera-se que o objetivo de objetivo mapear, classificar e analisar de forma integrada as unidades de paisagens e suas alterações entre os anos de 1984 e 2017 pode ser alcançado pela metodologia utilizada, as técnicas aqui empregadas podem ser replicadas em outras paisagens e seria interessante monitorar a Foz do Rio São Francisco em pesquisas futuras para acompanhar a evolução das unidades ora mapeadas e analisadas.

\section{Agradecimentos}

Os autores agradecem à CAPES pelas bolsas de pós-doutorado, doutorado e mestrado e ao CNPq pela bolsa de produtividade em pesquisa dos autores.

\section{Referências}

ALVES, N. M. S.; FONTES, A. L.; SILVA, D. B.; ALMEIDA, J. P. Dinâmica geoambiental, processos morfodinâmicos e uso das terras em Brejo Grande, baixo São Francisco - Sergipe. Revista Brasileira de Geomorfologia, v.8, n.2, p.11-21, 2007.

ALVES, N. M. S. Análise Geoambiental e Socioeconômica dos municípios costeiros do Litoral Norte do estado de Sergipe: diagnóstico como subsídio ao ordenamento e gestão do território. 2010. 348f. Tese (Doutorado em Geografia) - Núcleo de Pós-graduação em Geografia, Universidade Federal de Sergipe, São Cristóvão, 2010.

ALVES, N. M. S.; SILVA, D. B.; CARVALHO, I. S. M.; SANTANA, B. L. P.; ANDRADE, R. S. Mudanças no cotidiano das comunidades tradicionais pesqueiras de brejo grande - Sergipe, Brasil. Revista GeoNordeste, São Cristóvão, Ano XXVIII, n. 1, p. 187-202, Jan./Jun. 2017.

AMORIM, R. R.; OLIVEIRA, R. C. As unidades da paisagem como uma categoria de análise geográfica: o exemplo do município de São Vicente - SP. Sociedade \& Natureza, Uberlândia, v.2, n.20, p. 177-198, dez. 2008.

ARAÚJO, Sérgio Silva de. Apropriação dos recursos naturais e conflitos socioambientais no baixo São Francisco em Sergipe e Alagoas. 2015. 359 f. Tese (Doutorado em Desenvolvimento e Meio Ambiente)Programa de Pós-Graduação em Desenvolvimento e Meio Ambiente, Universidade Federal de Sergipe, São Cristóvão, 2015.

BERTRAND, G. Paisagem e Geografia Física Global: esboço metodológico. Cruz, Olga (trad.) Cadernos de Ciências da Terra. São Paulo, USP-IGEOG, nº 43, 1972.

BERTRAND, G.; BERTRAND, C. Uma geografia transversal e de travessias: o meio ambiente através dos territórios e das temporalidades. Maringá: Massoni, 2007.

BITTENCOURT, A. C. S. P.; MARTIN, L.; DOMINGUEZ, J. M. L.; FERREIRA, Y. A. Evolução paleogeográfica quaternária da costa do estado de Sergipe e costa sul do estado de Alagoas. Revista Brasileira de Geociências, São Paulo, v.13, n. 2, p. 93-97, 1983. 
BITTENCOURT A. C. S. P., OLIVEIRA M. B.; DOMINGUEZ J. M. L. Sergipe In: Muehe D. (org.). Erosão e progradação no litoral brasileiro. Brasília: MMA, 2006.

BOLÓS, M. de I. Capdevila. Problemática actual de los estúdios de paisaje integrado. Revista de Geografia, Barcelona, v. 15, n.1-2, enero-deciembre, 1981.

BOMFIM, L. F. C. Projeto Cadastro da Infra-Estrutura Hídrica do Nordeste: Estado de Sergipe. Diagnóstico do Município de Brejo Grande. CPRM: Aracaju, 2002.

CAILLEUX, A.; TRICART, J. Le problème de la classification des faits géomorphologiques. Ann. de Géogr.,V. 65, N. 162 -186, 1956.

CARVALHO, M. E. S.; FONTES, A. L. A carcinicultura no espaço litorâneo Sergipano. Revista da FAPESE, v. 3, n. 1, p. 87-112, 2007.

CPRM. Serviço Geológico do Brasil. Programa Levantamentos Geológicos Básicos do Brasil: Mapa Geológico do Estado de Sergipe, 2007. 65 p.

DINIZ. M. T. M. Bases para um plano de Gestão Integrada de Zonas Costeiras em Jacaúna - AquirazCE. 2008. 138f. Dissertação (Mestrado em Geografia). Programa de Pós-Graduação em Geografia, Universidade Estadual do Ceará, Fortaleza, 2008.

DINIZ, M. T. M.; OLIVEIRA, A. V. L. C. Mapeamento das unidades de paisagem do estado do Rio Grande do Norte, Brasil. Boletim Goiano de Geografia, v.38, N.2, p.342-364, 2018.

DINIZ, M. T. M.; OLIVEIRA, G. P. Compartimentação e Caracterização das Unidades de Paisagem do Seridó Potiguar. Brazilian Geographical Journal: geosciences and humanities research medium, v. 6, p. 291-318, 2015.

DINIZ, M. T. M.; OLIVEIRA, G. P.; BERNARDINO, D. B. S. M. Proposta de classificação das paisagens integradas. Revista de Geociências do Nordeste, v. 1, p. 50-69, 2015.

DINIZ, M. T. M; VASCONCELOS, F. P.; OLIVEIRA, G. P.; BERNARDINO, D. B. S. M. Geografia Costeira do Nordeste: bases naturais e tipos de uso. 1. ed. Curitiba: CRV, 135p. 2016.

DOMINGUEZ J. M. L., BITTENCOURT A. C. S. P., SANTOS A. N., NASCIMENTO L. The Sandy Beaches of the States of Sergipe-Alagoas. In: SHORT A. D., KLEIN A. H. F. (Orgs.). Brazilian Beach Systems. 1ed. Switzerland: Springer International Publishing, p. 281-305, 2016.

FORMOSO, L. C. Erosão e sedimentação no Delta do São Francisco: considerações sobre a interferência dos barramentos no sistema costeiro. Monografia (Graduado em Engenharia Ambiental). Instituto de Geociências e Ciências Exatas, Universidade Estadual Paulista, 2008.

ICMBio. Instituto Chico Mendes de Conservação da Biodiversidade. Plano de Manejo: Área de Proteção Ambiental de Piaçabuçu. Instituto Brasileiro de Geografia e Estatística. Brasília: MMA/ICMBio, 2010.

ILHA, D. B. Mapeamento e caracterização da carcinicultura no extremo norte do litoral sergipano. Anais do Simpósio Regional de Geoprocessamento e Sensoriamento Remoto - GEONORDESTE, Salvador, 2017.

MELO e SOUZA, R. Redes de monitoramento socioambiental e tramas da sustentabilidade. Geoplan, São Paulo: Annablume, 2007.

MEIRELES, A. J. A. Geomorfologia Costeira: funções ambientais e sociais. Fortaleza: Imprensa Universitária, 2014.

MEIRELES, A. J. A.; RAVENTOS, J. S. Y. Os promontórios e as dunas mantenedoras de um aporte regulador de sedimentos ao longo da linha de praia. Ceará, Brasil. Jornal de Gerenciamento Costeiro Integrado para Países de Língua Portuguesa, Santa Catarina, v. 2, p. 1-4, 2002.

OLIVEIRA, T. R. de A. Meu lugar é o Rio: aspectos identitários e territoriais da comunidade de pescadores artesanais do povoado Resina, Brejo Grande/SE. 2012. 82f. Dissertação (Mestrado em Ecologia Humana e Gestão Socioambiental). Programa de Pós-Graduação em Ecologia Humana e Gestão Socioambiental, Universidade do Estado da Bahia, Paulo Afonso, 2012.

RODRIGUES, F. G. de S.; KELTING, F. M. S. Paisagem e carcinicultura marinha no estuário do rio Jaguaribe - Aracati - Ceará. Revista GeoNordeste, São Cristóvão, Ano XXI, n.1, 2010. 
SANTANA, B. L. P; ALVES, N. M. S.; ANDRADE, R. S.; FARIAS, M. C. V. Interações dos processos ambientais na paisagem do município costeiro de Brejo Grande/Sergipe. Salvador: III Seminário Nacional Espaços Costeiros, 2016.

SANTOS, H. G. dos; JACOMINE, P. K. T.; ANJOS, L. H. C. dos; OLIVEIRA, V. A. de; LUMBRERAS, J. F.; COELHO, M. R.; ALMEIDA, J. A. de; ARAUJO FILHO, J. C. de; OLIVEIRA, J. B. de; CUNHA, T. J. F. Sistema Brasileiro de Classificação de Solos. 5. ed. rev. e ampl. Brasília: Embrapa, 2018.

SEMARH. Secretaria de Estado do Meio Ambiente e dos Recursos Hídricos de Sergipe. Programa de Ação Estadual de Combate a Desertificação PAE Final. Aracajú, 2011.

SOCHAVA, V. B. O estudo de geossistemas. Métodos em questão. Universidade de São Paulo. São Paulo: Instituto de Geografia, 1977.

TRICART, J. Ecodinâmica. Rio de Janeiro: IBGE/SUPREN, 1977. 